\title{
Surface features of chromium alloyed carbon steel specimens after salt-spray tests in $\mathrm{NaCl}$ solution
}

\author{
Varga, G. ${ }^{a}$, Török, T. ${ }^{\mathrm{b}}$, Felho, C. ${ }^{\mathrm{a},{ }^{*}}$, Orosz-Szirmai, G. ${ }^{\mathrm{b}}$, Réz, I. $^{\mathrm{c}}$ \\ ${ }^{a}$ Institute of Manufacturing Science, University of Miskolc, Miskolc, Hungary \\ ${ }^{b}$ Institute of Metallurgy, University of Miskolc, Miskolc, Hungary \\ 'Starters E-Components Generators Automotive Hungary Ltd, Miskolc, Hungary
}

\begin{abstract}
A B S T R A C T
The most common corrosion testing procedures use flat test coupons fabricated from a given steel material. However, workpieces that undergo machining and finishing, especially those with complex geometry, may be more subject to surface degradation on their curved surfaces. In the long run, this may adversely affect the smooth operation of the tested component. This study investigates surface features of machined and finished chromium alloyed steel specimens with rather complex geometries. Changes in several important surface features (topography, roughness, cylindricity, chemical degradation rate and corrosion products) were all measured periodically (after 24, 96 and 192 hours) on several sets of manufactured carbon steel planetary axle specimens exposed to a chemically aggressive medium (aqueous $\mathrm{NaCl}$ spray) at $35^{\circ} \mathrm{C}$. In the neutral salt spray (NSS) testing cabinet the cylindrical parts of the chromium alloyed carbon steel shafts showed quite severe and uneven chemical degradation, with the formation of several iron oxide-hydroxide products (rust) observed together with some chromium compounds. After careful removal of the relatively loose corrosion products, the exposed bare shaft surface's geometrical changes showed steady (close to linear) increase in the roughness values throughout the duration of the corrosion tests. This chemical attack caused significant changes in the surface topography as well. It was found that the average values of roughness parameters after the 24hour test were about two and a half times higher than the original values, while they increased by four-fold in the 96-hour test and by approximately eightfold in the 192-hour test. Furthermore, it was found that the values of the $3 \mathrm{D}$ roughness parameters $(\mathrm{Sa}, \mathrm{Sz}, \mathrm{Sq})$ are on average twice that of their $2 \mathrm{D}$ counterparts $(\mathrm{Ra}, \mathrm{Rz}, \mathrm{Rq})$ on the corroded surfaces. Circularity and roundness error data showed a similar increase with salt-spray test time duration.
\end{abstract}

\section{ARTICLE INFO}

Keywords:

Surface features;

Surface topography;

Roundness error;

Cylindricity deviation;

Corrosion;

Surface roughness;

Carbon steel;

Chromium alloyed steel;

Salt-spray test;

$\mathrm{NaCl}$ solution

*Corresponding author:

csaba.felho@uni-miskolc.hu

(Felho, C.)

Article history:

Received 15 February 2019

Revised 23 September 2019

Accepted 25 September 2019

\section{References}

[1] Li, Y., Cheng, Y.F. (2016). Effect of surface finishing on early-stage corrosion of a carbon steel studied by electrochemical and atomic force microscope characterizations, Applied Surface Science, Vol. 366, 95-103, doi: 10.1016/ j.apsusc.2016.01.081.

[2] Bajt Leban, M., Mikyška, Č., Kosec, T., Markoli, B., Kovač, J. (2014). The effect of surface roughness on the corrosion properties of type AISI 304 stainless steel in diluted $\mathrm{NaCl}$ and urban rain solution, Journal of Materials Engineering and Performance, Vol. 23, No. 5, 1695-1702, doi: 10.1007/s11665-014-0940-9.

[3] Xu, M., Zhang, Q., Yang, X., Wang, Z., Liu, J., Li, Z. (2016). Impact of surface roughness and humidity on X70 steel corrosion in supercritical CO2 mixture with SO2, H2O, and 02, The Journal of Supercritical Fluids, Vol. 107, 286297, doi: 10.1016/i.supflu.2015.09.017. 
[4] Pradhan, D., Mahobia, G.S., Chattopadhyay, K., Singh, V. (2018). Effect of surface roughness on corrosion behavior of the superalloy IN718 in simulated marine environment, Journal of Alloys and Compounds, Vol. 740, 250-263, doi: 10.1016/j.jallcom.2018.01.042.

[5] Yayoglu, Y.E. (2016). Corrosion characteristics of magnesium under varying surface roughness conditions, Graduate theses and dissertations, University of South Florida, USA.

[6] Walter, R., Kannan, M.B. (2011). Influence of surface roughness on the corrosion behaviour of magnesium alloy, Materials \& Design, Vol. 32, No. 4, 2350-2354, doi: 10.1016/j.matdes.2010.12.016.

[7] Almansour, A., Azizi, M., Jesri, A.M., Entakly, S. (2015). Effect of surface roughness on corrosion behavior of aluminum alloy 6061 in salt solution (3.5\% NaCl), International Journal of Academic Scientific Research, Vol. 3, No. 4, 37-45.

[8] Seo, M.J., Shim, H.-S., Kim, K.M., Hong S.-I., Hur, D.H. (2014). Influence of surface roughness on the corrosion behavior of Alloy 690TT in PWR primary water, Nuclear Engineering and Design, Vol. 280, 62-68, doi: 10.1016/ ¡.nucengdes.2014.08.023.

[9] Hagen, C.M.H., Hognestad, A., Knudsen, O.Ø., Sørby, K. (2019). The effect of surface roughness on corrosion resistance of machined and epoxy coated steel, Progress in Organic Coatings, Vol. 130, 17-23, doi: 10.1016/ i.porgcoat.2019.01.030.

[10] Lee, S.M., Lee, W.G., Kim, Y.H., Jang, H. (2012). Surface roughness and the corrosion resistance of $21 \mathrm{Cr}$ ferritic stainless steel, Corrosion Science, Vol. 63, 404-409, doi: 10.1016/i.corsci.2012.06.031.

[11] Kostadin, T., Cukor, G., Jakovljevic, S. (2017). Analysis of corrosion resistance when turning martensitic stainless steel X20Cr13 under chilled air-cooling, Advances in Production Engineering \& Management, Vol. 12, No. 2, 105114, doi: 10.14743/apem2017.2.243.

[12] Toloei, A., Stoilov, V., Northwood, D. (2013). The relationship between surface roughness and corrosion, In: Proceedings of the ASME 2013 International Mechanical Engineering Congress and Exposition, San Diego, California, USA, doi: 10.1115/IMECE2013-65498.

[13] Gathimba, N., Kitane, Y., Yoshida, T., Itoh, Y. (2019). Surface roughness characteristics of corroded steel pipe piles exposed to marine environment, Construction and Building Materials, Vol. 203, 267-281, doi: 10.1016/ j.conbuildmat.2019.01.092.

[14] Rishikesan, V., Samuel, G.L. (2014). Evaluation of surface profile parameters of a machined surface using confocal displacement sensor, Procedia Materials Science, Vol. 5, 1385-1391, doi: 10.1016/i.mspro.2014.07.456.

[15] Whitehouse, D.J. (2011). Handbook of Surface and Nanometrology, 2nd edition, CRC Press, Boca Raton, USA, doi: $10.1201 / \mathrm{b} 10415$

[16] Alcántara, J., de la Fuente, D., Chico, B., Simancas, J., Diaz, I., Morcillo, M. (2017). Marine atmospheric corrosion of carbon steel: A Review, Materials, Vol. 10, No. 4, 406, doi: 10.3390/ma10040406.

[17] Roine, A. (2002). Outokumpu HSC Chemistry, Version 5.1, Chemical reaction and equilibrium software with extensive thermochemical database, Outokumpu Research Oy, Finland.

[18] Jiang, S., Chai, F., Su, H., Yang, C. (2017). Influence of chromium on the flow-accelerated corrosion behaviour of low alloy steels in 3.5\% NaCl solution, Corrosion Science, Vol. 123, 217-227, doi: 10.1016/i.corsci.2017.04.024.

[19] Verma, C., Ebenso, E.E., Quraishi, M.A. (2017). Corrosion inhibitors for ferrous and non-ferrous metals and alloys in ionic sodium chloride solutions: A review, Journal of Molecular Liquids, Vol. 248, 927-942, doi: 10.1016/ j.molliq.2017.10.094 


\title{
Površinske značilnosti preizkušancev iz kromiranega ogljikovega jekla po preizkusih s solnim razpršilom z raztopino $\mathrm{NaCl}$
}

\author{
Varga, G. ${ }^{a}$, Török, T. ${ }^{b}$, Felho, C. ${ }^{a,}{ }^{,}$, Orosz-Szirmai, G. ${ }^{b}$, Réz, I. ${ }^{c}$ \\ ${ }^{a}$ Institute of Manufacturing Science, University of Miskolc, Miskolc, Hungary \\ ${ }^{\mathrm{b}}$ Institute of Metallurgy, University of Miskolc, Miskolc, Hungary \\ ${ }^{c}$ Starters E-Components Generators Automotive Hungary Ltd, Miskolc, Hungary
}

\section{POVZETEK}

Najpogosteje se pri preizkušanju proti koroziji uporabljajo ravni preizkušanci, izdelani iz danega jeklenega materiala. Vendar so obdelovanci, ki so podvrženi grobi in fini mehanski obdelavi, zlasti tisti s kompleksno geometrijo, degradaciji bolj podvrženi na ukrivljenih površinah. Dolgoročno lahko to negativno vpliva na nemoteno delovanje preizkušene komponente. Ta študija raziskuje površinske značilnosti grobo in fino obdelanih preizkušancev iz kromiranega jekla z razmeroma kompleksnimi geometrijami. Spremembe v več pomembnih površinskih značilnostih (topografija, hrapavost, valjnost, stopnja kemične razgradnje in korozija) so bile periodično merjene (po 24, 96 in 192 urah) na več sklopih preizkušancev iz planetne gredi iz ogljikovega jekla, ki so bili izpostavljeni kemično agresivnemu mediju (vodno razpršilo $\mathrm{NaCl}$ ) pri $35^{\circ} \mathrm{C} . \mathrm{V}$ komori za nevtralno razprševanje soli (NSS) so cilindrični deli gredi iz legiranega ogljikovega jekla pokazali znake precej hude in neenakomerne kemične degradacije, pri čemer je bilo skupaj z nekaterimi kromovimi spojinami opaziti več področij nastanka železovega oksida-hidroksida (rje). Po skrbnem odstranjevanju relativno ohlapne korozije, so izpostavljene cone gredi pokazale enakomerno (skoraj linearno) povečanje hrapavosti v času trajanja korozijskih preskusov. Ta kemični udar je povzročil tudi pomembne spremembe na površinski topografiji. Ugotovljeno je bilo, da so bile povprečne vrednosti hrapavosti po 24-urnem preizkusu približno dvainpolkrat višje od prvotnih vrednosti, medtem ko so se v 96-urnem preizkusu povečale za štirikrat in za približno osemkrat pri 192-urnen preizkusu. Poleg tega je bilo ugotovljeno, da so na korodiranih površinah vrednosti parametrov 3D hrapavosti (Sa, Sz, Sq) v povprečju dvakrat večje od vrednosti parametrov 2D hrapavosti $(R a, R z$, Rq). Podatki o napakah v krožnosti in okroglosti so pri preizkusih s solnim razpršilom glede na čas pokazali podobno povečanje.

\section{PODATKI O ČLANKU}

Ključne besede:

Površinske značilnosti;

Površinska topografija;

Napaka okroglosti;

Odstopanje valjnosti;

Korozija;

Hrapavost površine;

Ogljikovo jeklo;

Kromirano jeklo;

Preizkusi s solnim razpršilom;

Raztopina $\mathrm{NaCl}$

*Kontaktna oseba:

csaba.felho@uni-miskolc.hu

(Felho, C.)

Zgodovina članka:

Prejet 15. februarja 2019

Popravljen 23. septembra 2019

Sprejet 25. septembra 2019 